\title{
Cortisona en el tratamiento de esterilidad femenina por obstrucción tubárica ${ }^{(*)}$
}

\author{
Doctor Hernando Amaya-León
}

Profesor Agregado de Ginecología. Universidad Nacional de Colombia.

La significación del factor tubárico como causa etiológica definida en la esterilidad femenina es tan conocida que no vale la pena insistir en ella; recordamos tan solo el dato de Rubin (1), quien revisando 43.930 historias clínicas, estima tal factor tubárico como causante del $47 \%$ de los casos.

De ahí la preocupación constante de quienes trajinamos con asuntos de fertilidad conyugal, en conocer y procurar tratar tan importante factor. Para todos, no es infrecuente el éxito obtenido con pruebas de Rubin repetidas, histerosalpingografías, antibióticos, etc., pero bien sabemos que hay un cierto número, apreciable sin duda, de casos de obstrucción tubárica que permanecen inalterables a las terapéuticas conocidas.

Estos casos deberían ser propuestos para cirugía reparadora; y a menudo lo son. Pero los resultados de las tuboplastias y procedimientos afines son tan poco confortantes, que honestamente debe pensarse mucho antes de abocar la cuestión operatoria.

Es por esto, que cualquier terapéutica conservadora tendiente a corregir obstrucciones tubáricas merece todo nuestro interés.

En 1952, Collins y col. (2), obtuvieron los primeros resultados favorables al usar cortisona en 7 casos de celulitis pélvica, observados en Tulane Charity Hospital de New Orleans; sin embargo, su relación no tenía la esterilidad como objetivo.

En diciembre de 1954, Kurzrok y Streim (3), publicaron su reporte preliminar sobre el uso de cortisona en el tratamiento de la esterilidad, debida a trompas impermeables; el esquema terapéutico empleado por ellos fue el siguiente: 50 miligramos de "cortogen" diarios, por vía oral, exceptuando el período menstrual, y 100 miligramos por vía muscular, dos veces a la semana, agre-

(*) Trabajo presentado al III Congreso Colombiano de Obstetricia y Ginecología, reunido en Ibagué. 1957. 
gando diatermia, dos veces semanales; la terapia instituida se continuaba durante 3 o 4 meses.

Sus resultados fueron extraordinarios: en 8 pacientes asi tratadas, obtuvieron embarazo en 5 casos; y en los 3 restantes, comprobaron definida permeabilización tubárica; no hubo efectos marcados desfavorables.

Notablemente ilusionados por el éxito obtenido por los autores de New York, iniciamos observaciones en nuestros casos. Hé aquí los resultados:

Caso número 1.-M. C. de S., 34 años, esterilidad de seis años. Exámenes clínicos satisfactorios; ovulación comprobada; espermograma normal; pruebas de Rubin negativas en varias ocasiones. Radiografías (doctor Mariño, 5234-3960): "Obstrucción tubárica bilateral". Se inicia tratamiento exáctamente indícado por los autores mencionados, durante cuatro meses. Nuevas radiografías en noviembre 1955, indican tan solo que "la trompa derecha da paso al medio opaco hasta el tercio interno; resto igual". Ha sido controlada hasta febrero de 1957, haciendo persuflaciones y lavados endouterinos con diversas sustancias durante todo el año anterior. Las trompas continúan obstruídas; cirugía ha sido propuesta como último recurso.

De entonces para acá, y con la aparición de los nuevos esteroides descubiertos, prednisona y prednisolona, resolvimos modificar el esquema de Kurzrok y Streim de la siguiente manera:

a) Prednisona o prednisolona: 15 miligramos diarios durante dos meses, y luego reducción progresiva hasta cuatro meses. Al final, inyecciones de ACTH.

b) Diatermia: dos veces a la semana.

c) Persuflaciones tubáricas: una vez al mes, a presiones altas y sostenidas.

d) Irrigaciones endouterotubáricas con una solución de hidrocortisona o suspensión de prednisolona a la que se habían agregado 20 unidades de hialurodinasa (kynadena): una vez al mes.

Casa número 2.-C. D. de M.: treinta y un años. Esterilidad de doce años. Pruebas de rutina, normales. Radiografías (doctor M. - 6074-4578) : "Hidrosalpinx bilateral". Se inicia tratamiento con el esquema indicado. Resultados: negativos completos para obstrucción tubárica, y obviamente también para gestación. 
Caso número 3.-C. B. de H., veintitrés años. Esterilidad de tres años. Al examen clinico, moderada hipoplasia uterina y de senos. Biopsias de endometrio y tests de ovulación, normales; metabolismo basal, citología vaginal, dentro de los límites normales; espermograma, Huhner: satisfactorios. Pruebas de Rubin, negativas. Radiografías (doctor M. - 6572-5079): "Hipoplasia- tubaria con hidrosalpinx bilateral y obstrucción terminal". En febrero de 1956 se inicia tratamiento según esquema, el cual termina en junio, habiéndose obtenido en mayo una prueba de persuflación francamente positiva. La paciente se deja en observación por tres meses; en diciembre de 1956, un Rubin es negativo, pero posteriores persuflaciones y lavados con hidrocortisona logran permeabilidad neta. Actualmente está en estrogenoterapia, buscando maduración genital. El último Rubin, en octubre 1957. es positivo sin dudas.

Caso número 4.-C. M. de L., veintiocho años. Esterilidad de tres años. Himenotomía a los dieciséis años por hematocolpos. Las radiografías (doctor M. - 3129-2443), demuestran "hidrosalpinx bilateral". El tratamiento se inicia en julio de 1956, practicándose en su totalidad. Los controles hasta hace pocos meses continuaban demostrando la obstrucción tubárica. Ha sido propuesta para cirugía reparadora.

Caso número 5.-M. T. de P., de treinta y dos años. Esterilidad de siete años. En 1952, un médico practicó salpingectomía izquierda y plastia en la derecha, en circuncisión de la extremidad ampular y lisis de adherencias. Radiografías (Clínica Palermo, 1955): "no hay visualización de la trompa izquierda; hiđrosalpinx derecho". Se inicia tratamiento en abril de 1957, terminancio en julio. Pruebas efectuadas, totalmente negativas. Está en observación.

Como es fácil apreciar, los resultados son completamente desfavorables, pues no se ha obtenido ningún embarazo, y tan solo un caso de permeabilización tubárica satisfactoria, a pesar de que el esquema de tratamiento usado en estos casos podría ser considerado como más completo que el aconsejado por Kurzrok y Streim.

Llama la atención, a pesar de tratarse de un tema tan interesante, no encontrar referencias posteriores ni de los autores originales ni de otros, sobre nuevos resultados. Se exceptúan Wills y col. (4), de Houston (Texas), que en 1956 reportan resul- 
tados muy favorables en el tratamiento de 10 casos de enfermecad pélvica inflamatoria crónica recurrente con cortisona asaciada a tetraciclina, de los cuales, en 2 anotan embarazo, luego de esterilidad secundaria, aunque haciendo la advertencia precisa de que en ellos habia dispareunia previa tan intensa que hacfa el coito muy infrecuente.

\section{RESUMEN}

1. La cortisona, prednisona y prednosolona han sido empleadas como tratamiento de base en 5 casos de esterilidad femenina consecutiva a obstrucción tubárica.

2. Los resultados han sido francamente negativos, con excepción de un éxito relativo en donde se obtuvo permeabilidad permanente.

\section{REFERENCIAS}

1. RUBIN I. C.-Cit. por Siegler s. I. Fertility in Women. J. B. Lippincott Co., 1944, p. 238.

2. COLLINS C. G., DAVIDSON V. A., MATHEWS N. V.-Use of Cortisone in Pelvic Celulitis. New Orleans Med. and Surg., 104: 385, 1952.

3. KURZROK L., ST'REIM E.-Cortogen Treatment for Sterility Due to Nonpatent Tubes. Preliminary Report. Fertil. \& Steril., 5: 515, 1954.

4. WILLS S. H., JACOBS W. M., LAUDEN A. E.-Cortisone and Tetracycline in Chronic Recurrent PID. Obst. \& Gymec., 7: 689, 1956.

Consultorio de Especialistas.

Carrera 13, número 43-23, Bogotá (Colombia). 